\title{
54 Neoplastic disease of the external ear
}

A Exostoses are the commonest benign tumours of the cartilage.

B Ceruminomas are easily cured by simple excision.

C Squamous carcinoma may be associated with xeroderma pigmentosa.

D Basal cell carcinomas are usually seen in the external meatus.

E An osteoma is composed of ivory bone.

\section{In the external auditory meatus}

A Ceruminous and pilosebaceous glands are located in the cartilaginous meatus.

B Keratosis obturans may be associated with bronchiectasis and sinusitis.

C Chronic otitis externa may produce a fibrous stenosis.

D Vegetable foreign bodies should be syringed with saline.

E Live insects may be killed with insecticide spray.

\section{Congenital anomalies of the middle ear cleft}

A Due to their common origin the outer, middle and inner ear elements are all effected.

B Congenital conductive deafness with a normal meatus and eardrum is easily corrected surgically.

C The Treacher-Collins syndrome is an expression of ear anomalies associated with other developmental defects of the 1st and 2nd branchial arches.

D High definition CT scan is essential prior to any surgical intervention.

E Wildervanck's syndrome is a conductive deafness associated with preauricular sinuses and appendages and auricular malformations. 